\section{Biossegurança na OdONTOLOGia}

Maria Valéria Argente Santos* Fabiana Bueno de Godoy Camos* Juliana Alvares Duarte Bonini Campos**

\section{Introdução}

A lógica da construção do conceito de biossegurança teve seu início na década de 70, na Califórnia, e, segundo Goldim (1997), foi um marco na história da ética aplicada à pesquisa, pois foi a primeira vez que se discutiu os aspectos de proteção aos pesquisadores e demais profissionais envolvidos nas áreas de saúde. A partir daí, o termo biossegurança vem, ao longo dos anos, sofrendo alterações.

Com o aumento e aparecimento de doenças infecto-contagiosas, os conceitos de biossegurança cresceram em importância. Um assunto tratado com pouca atenção há algum tempo atrás e que passou por um período de desconfiança por parte dos pacientes, atualmente atingiu um estágio em que eles já não aceitam serem atendidos sem os devidos cuidados.

O controle de infecção e a biossegurança são temas de grande relevância para a prática odontológica, e esse assunto vem despertando um interesse cada vez maior dos profissionais preocupados com uma prática séria e de qualidade.

A odontologia vem enfrentando muitos desafios desde a primeira publicação, em 1978, das recomendações sobre controle de infecção pela American Dental Association. Estudos subseqüentes documentaram o aumento do risco de infecção por Hepatite B na prática odontológica, fazendo com que, a partir de 1982, vacinas fossem disponibilizadas para prevenção destas infecções dentre os cirurgiões-dentistas.

Depois da descrição dos primeiros casos de AIDS nos anos 80, houve um interesse renovado para delinear melhor e demonstrar o desafio do controle de infecção para os cirurgiões-dentistas que, por sua vez, precisam constantemente se atualizar sobre as formas de controle de infecção, produtos

* Alunas do curso de Odontologia do Centro Universitário de Araraquara - Uniara.

** Profa. Dra. da disciplina de Odontologia em Saúde Coletiva e Orientação Profissional do

Centro Universitário de Araraquara - Uniara. disponíveis e procedimentos a serem adotados (JABUR, SCABELL, 2002).

Jabur e Scabell (2002) afirmam que a descontaminação de instrumentos impregnados com material ou fluidos orgânicos provenientes do paciente é uma fase essencial no controle das infecções passíveis de serem adquiridas na clínica odontológica. Os cuidados a serem empregados no controle de infecções cruzadas incluem medidas que compreendem precauções universais (higiene pessoal, utilização de barreiras de proteção), imunização, esterilização de instrumentais e atualização freqüente na área de conhecimento (biossegurança).

A esterilização dos instrumentais deve ser sempre realizada antes e após o contato com os fluídos provenientes do paciente (sangue e saliva). O processo de esterilização em unidades de ensino e pesquisa (universidades, faculdades e centros de pesquisa) deve ser realizado em locais apropriados e por pessoal treinado, nas chamadas unidades ou centrais de esterilização.

Gomes et al. (2001) descrevem que entre os vários preceitos e diretrizes que envolvem a odontologia moderna estão a divulgação e a inserção de normas e padrões de biossegurança da prática odontológica. Nesse sentido, faz-se necessária à consciência de profissionais e pacientes do significado da saúde bucal no contexto da saúde integral e da importância da biossegurança no controle de riscos operacionais.

Assim, entende-se que "a Biossegurança é o conjunto de ações voltadas para a prevenção, minimização ou eliminação de riscos inerentes às atividades de pesquisa, produção, ensino, desenvolvimento tecnológico e prestação de serviços, que podem comprometer a saúde do homem, dos animais, do meio ambiente ou a qualidade dos trabalhos desenvolvidos” (COMISSÃO DE BIOSSEGURANÇA DA FUNDAÇÃO OSWALDO CRUZ, 2001).

A prática da odontologia abrange uma grande variedade de procedimentos, que podem incluir desde um simples exame até um tratamento curativo mais complexo. Estes procedimentos geralmente implicam em contato com secreções da cavidade bucal, como saliva, sangue, secreções purulentas, respiratórias e aerossóis. Isso tudo acaba resultando em possibilidade de transmissão de infecções, tanto de paciente para paciente, como dos profissionais para pacientes ou dos pacientes para os profissionais (KONKEWICZ, 2000).

\section{Discussão}

A II Conferência Nacional de Saúde Bucal (1993) já havia ressaltado e recomendado aos gestores de serviços de saúde a importância de melhorar a estruturação do atendimento odontológico, de forma a possibilitar o cumprimento das normas de biossegurança e controle das infecções das unidades públicas e privadas; a obrigatoriedade da coleta do lixo odontológico e a integração da atenção odontológica aos programas de saúde do trabalhador e 
de segurança do trabalho, viabilizando a detecção dos riscos específicos e assegurando aos trabalhadores a pesquisa da causa e da relação do trabalho com o aparecimento de doenças.

Os fatores supracitados referem-se ao controle do ambiente de trabalho, incluindo posturas e posições de trabalho bem como a conscientização dos riscos inerentes à prática profissional e, principalmente, seu controle.

A incorporação de normas de biossegurança significa coerência e responsabilidade com os preceitos de saúde (GOMES et al., 2001).

De acordo com Porto (1994), a ergonomia é a aplicação das Ciências Biológicas, em conjunto com as Ciências Mecânicas, para conseguir a melhor adaptação mútua do homem à sua ocupação, visando prosperidade e maior eficiência, tendo como objetivo a simplificação do trabalho, a prevenção da fadiga, diminuição de acidentes de trabalho, preservação da saúde, aumento da produtividade e o maior conforto, tanto do cirurgião-dentista quanto do paciente. Deste modo, entende-se que os riscos ocupacionais podem e devem ser evitados através da observância das normas técnicas de biossegurança.

Dos problemas ocupacionais, a postura de trabalho é um dos mais preocupantes, pois dela derivam situações graves como dores musculares na região dorsal, lombar, pernas, braços e pés, cefaléias, perturbações circulatórias e varizes, bursite dos ombros e cotovelos, inflamações de tendões, problemas de coluna com alterações cervicais, dorsais e lombares, fadiga dos olhos e desigualdade da altura dos ombros (artrite cervical) (COMISSÃO DE BIOSSEGURANÇA DA FUNDAÇÃO OSWALDO CRUZ, 2001).

Medidas efetivas de controle de infecção visam eliminar ou minimizar o risco de transmissão de infecções na rotina odontológica. Várias revisões sobre o assunto e recomendações têm sido publicadas no sentido de orientar os profissionais nessa prática (MILLER, PALENIK, 1991).

Apesar do risco de transmissão de HBV e HIV entre pacientes e profissionais na prática odontológica despertar grande preocupação, o Ministério da Saúde (1996) considera esta possibilidade de transmissão baixa. De acordo com Rimland et al. (1977) e Beekmann e Henderson (1994) alguns relatos de transmissão de HIV e HBV de pacientes para profissionais e profissionais para pacientes têm sido publicados sem, entretanto, identificar claramente as vias de contágio.

Os acidentes punctórios permanecem, ainda, como os maiores responsáveis pela transmissão de HBV e HIV para os profissionais de saúde em geral (CLEVELAND, GOOCH, LOCKWOOD, 1997; GARNER, 1996). Em virtude de que nem todos os pacientes portadores de HIV, HBV ou outros patógenos importantes possam ser identificados previamente à realização de um procedimento invasivo, é recomendado que todos os pacientes, indiscriminadamente, sejam considerados potencialmente de risco e que, conseqüentemente, precauções devem ser utilizadas em todos os procedimentos, com todos os pacientes (HAMORY, WHITENER, 1999).

A crescente aderência às precauções e recomendações de biossegurança tem contribuído para a diminuição dos riscos de transmissão de infecções na prática odontológica (MINISTÉRIO DA SAÚDE, 1996; GONÇALVES, PORDENS, 1997; MINISTÉRIO DA SAÚDE, 1998). Entretanto, em estudos recentes, percebe-se que existe pouco domínio do assunto por parte da comunidade acadêmica do Brasil e de outros países (RÉUS, 2002).

Percebe-se hoje um grande interesse com relação ao controle de infecção por parte dos dentistas e demais profissionais da área de saúde. Centenas de trabalhos são apresentados a cada ano em diferentes congressos, jornais, revistas e livros. Apesar de serem muitas as fontes de informação, ainda persistem muitas dúvidas e preocupações a respeito da correta aplicação das medidas de controle de infecção na clínica. Portanto, é de fundamental importância uma ampla campanha de esclarecimento junto aos profissionais e estudantes, de modo a melhorar conhecimentos, atitudes e procedimentos de controle de infecção (RUTALA, 1996).

No Quadro 1 abaixo estão algumas medidas de proteção fundamentais para uma prática odontológica salutar.

Quadro 1 - Medidas de proteção para prática odontológica salutar.

\begin{tabular}{|c|c|}
\hline \multicolumn{2}{|r|}{ BARREIRAS DE PROTEÇÃO } \\
\hline Profissional e equipe & $\begin{array}{l}\text { - jaleco de manga longa } \\
\text { - gorro descartável } \\
\text { - máscara descartável } \\
\text { - óculos de proteção } \\
\text { - luvas descartáveis }\end{array}$ \\
\hline Pacientes & $\begin{array}{l}\text { - óculos de proteção } \\
\text { - babador } \\
\text { - proteção equipo, cadeira e refletor com filme de PVC } \\
\text { - tratamento (desinfecção e/ou esterilização) de materiais e } \\
\text { instrumental }\end{array}$ \\
\hline Bloqueio epidemiológico & - vacinas: hepatite, sarampo, tétano, gripe \\
\hline Aspectos ergonômicos & $\begin{array}{l}\text { - postura e posição de trabalho } \\
\text { - montagem do consultório odontológico } \\
\text { - delegação de funções } \\
\text { - trabalho produtivo e racionalizado }\end{array}$ \\
\hline
\end{tabular}

Para a escolha adequada dos processos de utilização e tratamento dos materiais, estes devem ser divididos nas categorias críticos, semi-críticos e não críticos (MILLER,1993). Materiais críticos são aqueles que entram em contato direto com tecidos cruentos, materiais semi-críticos possuem contato 
apenas com mucosas e materiais não críticos são aqueles que só entram em contato com pele íntegra.

De uma forma geral, durante os processos de tratamento, os materiais críticos devem ser esterilizados ou de uso único (descartáveis), os materiais semicríticos devem sofrer esterilização ou no mínimo desinfecção e os materiais não críticos devem ser desinfetados ou limpos. A periodicidade dos processos de limpeza, desinfecção e esterilização dos materiais deve ser sempre realizada entre o uso em diferentes pacientes (RUTALA, 1999).

Todo o processo de limpeza, desinfecção ou esterilização de materiais deve ser centralizado em um local reservado. Portanto, após cada atendimento, todos os materiais utilizados devem ser levados para a sala de materiais, para seu adequado processamento. Os instrumentais não devem ser lavados na própria pia do consultório dentário, já que esta deve servir exclusivamente para lavagem de mãos ou outras necessidades durante os procedimentos (SECRETARIA DA SAÚDE DO ESTADO DO RIO GRANDE DO SUL, 2000).

A esterilização de artigos odontológicos pode ser realizada através de métodos químicos ou físicos (HOWARD, 1991; MILLER, 1992). A primeira compreende a utilização de agentes esterilizantes líquidos, que são os mesmos utilizados no processo de desinfecção, porém com maior tempo de exposição. A esterilização química apresenta alguns aspectos negativos, especialmente referentes ao risco de recontaminação do material após o processo, dificuldade de armazenamento e de controle de qualidade ou monitoramento do processo.

A esterilização física pode ser realizada por meio de métodos ou equipamentos que empregam calor seco (estufa) ou vapor saturado (autoclave) (HOWARD, 1991).

É indiscutível a necessidade de zelar pela própria saúde e pela saúde dos pacientes, e a cada momento esta preocupação se torna uma questão significativa na promoção e manutenção da qualidade de vida. Preocupados com isto, órgãos mundiais de saúde têm trabalhado no sentido de conscientizar não só os cirurgiõesdentistas, mas também os usuários dos serviços de odontologia, da importância de freqüentar ambientes onde a Biossegurança, caracterizada pelo cumprimento de um conjunto de normas e procedimentos, seja uma realidade (BORGES, 2002).

De acordo com Borges (2002), apesar do cirurgião-dentista brasileiro estar entre os melhores do mundo em nível estético e funcional, quando se cogita Biossegurança, ele se encontra lamentavelmente entre os mais pobres do mundo. O que segundo o autor representa um grande contra-senso, uma vez que o paciente atendido em condições de proteção biológica, conscientizado pelo profissional dos riscos de contaminação e infecção, manterá a fidelidade ao profissional.

Borges (2002) salienta ainda que a Biossegurança "é um caminho sem volta e depende de uma mudança de atitude profissional que beneficia a todos: paciente equipe odontológica e principalmente o cirurgião-dentista, que além de se proteger dá um grande diferencial à sua clínica”.

\section{Conclusão}

Frente ao exposto, pode-se concluir que a Biossegurança é fundamental para a execução de uma prática odontológica segura e salutar, que consiga promover e manter a saúde do profissional, paciente e de toda a equipe de trabalho.

\section{Referências:}

BARR, C. E. et al. Recovery of infectious HIV-1 from whole saliva. JADA Chicago, n.123, p.37-45, 1992.

BEEKMANN, S.E. ; HENDERSON, D.K. Managing occupational risks in the dental office: HIV and the dental professional. JADA, Chicago, n.125, p.847-852, 1994

BORGES L. Biossegurança, preservação da saúde é ferramenta de marketing na Odontologia atual, 2002. Disponível em:

<www.biossegurancaodonto.com.br>. Acesso em: 27 de Julho de 2005.

\section{COMISSÃO DE BIOSSEGURANÇA DA FUNDAÇÃO OSWALDO}

CRUZ, 2001.

CLEVELAND, J. L.; GOOCH, B. F.; LOCKWOOD, S. A. Occupational blood exposures in dentistry: a decade in review, Infect Control Hosp Epidemiol. Chicago, n.18, p.717-721, 1997.

GARNER, J. S. Guideline for isolation precautions in hospitals. Infect Control Hosp Epidemiol. Chicago, n.17, p.53-80, 1996.

GOLDIM, J. R. Conferência de Asilomar, 1997. Disponível em: <www.ufrgs.br/HCPA/gppg/asilomar.htm>. Acesso em: 27 de julho de 2005.

GOMES, A.C.L. et al. Divisão Estadual de Saúde Bucal de Pernambuco. Recife: Secretaria Estadual de Saúde, 2001, 126p.

GONÇALVES, P.M.J.; PORDEUS, I.A. Controle da infecção cruzada na prática odontológica por periodontistas de Belo Horizonte. Rev Periodontol, Rio de Janeiro, n.6, p.34-40, 1997. 
GOOCH, B. et al. Lack of evidence for patient-to-patient transmission of HIV in a dental practice. JADA, Chicago, n.124, p.38-44, 1993.

HAMORY, B.H.; WHITENER, C.J. Nosocomial infections in dental, oral, and maxillofacial surgery. In: MAYHALL, C.G. Hospital Epidemiology and Infection Control. 2. ed. Philadelphia: Lippincott Williams \& Wilkins, 1999. p. 719-728.

HOWARD, W.J. The controversy of flash sterilization. Today's OR Nurse, Thorofare, n.13, p.24-27, 1991.

JABUR, M.S.; SCABELL, P.L. Manual de Biossegurança da Faculdade de Odontologia da Universidade do Rio de Janeiro, 2002, 65p.

MILLER, C.H. Cleaning, sterilization and desinfection: basics of microbial killing for infection control. JADA, Chicago, n.124, p.48-56, 1993.

MILLER, C.H. Sterilization and desinfection: what every dentists needs to know. JADA, Chicago, n.123, p.46-54, 1992.

MILLER, C.H.; PALENIK, C.J. Sterilization, desinfection, and asepsis in dentistry. In: BLOCK, S.S. Desinfection, sterilization and preservation. 4. ed. Pennsylvania: Lea \& Febiger, 1991, p.676-695.

\section{MINISTÉRIO DA SAÚDE. Programa de Controle de Infecção}

Hospitalar. Portaria ${ }^{\circ}$ 2616, de 12 de maio de 1998. Diário Oficial, 13 maio de 1998, nº 89, p. 133-5.

MINISTÉRIO DA SAÚDE. Secretaria de Assistência à Saúde. Programa Nacional de DST/AIDS. Hepatites, AIDS e herpes na prática odontológica. Brasília, 1996. $54 \mathrm{p}$

PORTO, F.A. O Consultório Odontológico. São Carlos: Scritti, 1994.152 p.

KONKEWICZ, L.R. Controle de infecção em Odontologia. Disponível em: <http://www.cro-rj.org.br/biosseguranca>. Acesso em: 25 jan. 2005.

RÉUS, M. Biossegurança em consultório odontológico. Revista Racine, São Paulo, v. 12, 2002, p. 52-67.
RIMLAND, D. et al. Hepatitis B virus traced to an oral surgeon. New England J Med, Waltham, n.296, p. 953-8, 1977.

RUTALA, W.A. APIC guideline for selection and use of desinfectants. Am J Infect Control, St. Louis, n.24, p.313-342, 1996.

RUTALA, W.A. Selection and use of desinfectants in health care. In: MAYHALL, C.G. Hospital epidemiology and infection control. 2ed. Philadelphia: Lippincott Williams \& Wilkins, 1999, p.1161-1187.

SECRETARIA DA SAÚDE DO ESTADO DO RIO GRANDE DO SUL. Norma técnica de biossegurança em estabelecimentos odontológicos e laboratórios de prótese no Rio Grande do Sul. Portaria nº 40/2000 SES. 29 de dezembro de 2000.

\section{Resumo:}

A prática da odontologia abrange grande variedade de procedimentos, que podem incluir desde um simples exame clínico até uma cirurgia mais complexa. Estes procedimentos geralmente implicam em contato com secreções da cavidade bucal como saliva, sangue, secreções purulentas, respiratórias e aerossóis. O risco de transmissão de patógenos importantes tem despertado grande preocupação devido ao risco de exposição do paciente, do profissional e da equipe odontológica. Assim, recomenda-se que precauções padronizadas sejam utilizadas durante a rotina de tratamentos odontológicos. Deste modo, realizou-se este estudo com o objetivo de abordar aspectos importantes no controle dos fatores de risco à infecção cruzada na prática odontológica.

\section{Palavras-chave:}

Biossegurança, Odontologia, Saúde Ocupacional. 